\title{
Diagnóstico y evaluación de la situación del turismo en Ecuador y propuesta de acciones para enfrentar la crisis generada por el covid-19
}

DOI: https://doi.org/10.33262/ap.v1i1.19

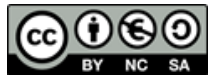

Diagnosis and evaluation of the tourism situation in Ecuador and proposal of actions to face the crisis generated by covid-19

Dariel Armstrong Zulueta. ${ }^{1} \&$ Thalía Rodríguez Deler. ${ }^{2}$

\begin{abstract}
.
The crisis caused by the COVID-19 virus has had a reach and consequences worldwide never before imagined, being one of the most affected sectors, tourism. That is why each country has the responsibility of studying the new normal to combat the effects of the crisis, so this research proposes the evaluation of the situation of tourism in Ecuador before the crisis, the consequences of this for the Ecuadorian tourism sector and the proposal of strategies that make it possible to reactivate tourist activity in the country. In addition, through the application of 300 questionnaires to managers, businessmen and entrepreneurs of tourist establishments registered by MINTUR, the most likely scenarios to be generated in the country were concluded.
\end{abstract}

Keywords: Crisis, COVID-19, Ecuador, tourims, strategies, scenarios.

\section{Resumen.}

La crisis ocasionada por el virus Covid-19 ha tenido un alcance y unas consecuencias a nivel mundial nunca antes imaginadas, siendo uno de los sectores más afectados, el turismo.

\footnotetext{
${ }^{1}$ Universidad de La Habana. Facultad de Turismo. La Habana, Cuba. darielarmstrong@gmail.com
}

${ }^{2}$ Universidad de La Habana. Facultad de Turismo. La Habana, Cuba. thaliarodriguez@ gmail.com 
Es por ello que cada país tiene la responsabilidad de estudiar la nueva normalidad para combatir de forma gradual los efectos de la crisis, por lo que esta investigación se propone una evaluación de la situación del turismo en Ecuador antes de la crisis, las consecuencias de esta para el sector turístico ecuatoriano y la propuesta de estrategias que posibiliten reactivar la actividad turística en el país. Además, a través, de la aplicación de 300 cuestionarios gerentes, empresarios y emprendedores de establecimientos turísticos registrados por el MINTUR, se concluyeron los escenarios más probables a generarse en el país.

Palabras claves: Crisis, covid-19, Ecuador, turismo, estrategias, escenarios.

\section{Introducción.}

La crisis del coronavirus es mayúscula. Configura, sin duda alguna, la mayor prueba para la sociedad humana globalizada. Y para Ecuador, un pequeño país colgado de la cordillera de los Andes, el reto resulta descomunal.

La economía mundial está siendo seriamente golpeada y el turismo enfrenta hoy día una de sus mayores crisis de todos los tiempos tras la extensión de la pandemia del COVID-19. Esta difícil situación de supervivencia que atraviesan las empresas y los destinos turísticos debe ser afrontada mediante estudios de diagnóstico turístico que contribuyan a una correcta toma de decisiones por parte de los organismos turísticos competentes (Félix \& García, 2020).

De manera consecuente con esta situación, la OMT a finales de enero empieza a realizar una serie de llamamientos a las autoridades mundiales para alertar sobre los daños que puede provocar esta epidemia al sistema turístico mundial y la necesidad de adoptar medidas urgentes de contención y choque. Este organismo previó entonces una caída de entre un $20 \%$ y un $30 \%$ en las llegadas internacionales, lo que podría traducirse en un declive de los ingresos por turismo internacional (exportaciones) de entre 300.000 y 450.000 millones de dólares americanos, o sea, casi un tercio del billón y medio de dólares alcanzado en 2019 (OMT, 2020b).

Actualmente el COVID-19 reporta afectaciones en 185 países de todo el mundo, con una cifra de contagios hasta de 7 de octubre de 35848269 personas y reporta 1048181 fallecidos (MINSAP, 2020).

Con este panorama nada alentador, se estima incluso que la actividad turística va a ser, a diferencia de lo ocurrido en anteriores crisis, una de las actividades económicas que más tarde va a volver a la normalidad en el engranaje económico mundial, lo que conlleva la necesaria y urgente aplicación de estrategias encaminadas a la mitigación de daños y la planificación para la recuperación mediante la colaboración público-privada entre las autoridades nacionales y locales y el sector empresarial privado (Félix \& García, 2020).

\section{Metodología.}


La presente investigación muestra en primer lugar un diagnóstico de la situación de Ecuador como destino turístico antes de la propagación de la pandemia por el mundo. Se caracteriza la situación turística en cuanto a ingresos al país por turismo, llegadas internacionales, situación del turismo interno e infraestructura turística. Posteriormente se realiza un diagnóstico de la situación actual de Ecuador ante la pandemia a partir de un repaso de la información noticiosa e informes oficiales más relevantes promovidos por organismos oficiales en los últimos cuatro meses del 2020 y para terminar esta revisión se han identificado los factores que sustentan la percepción de la actividad turística en momentos de crisis, tanto por parte de los actores locales como de la demanda turística real y potencial.

Se diseñó un cuestionario como técnica de investigación, con preguntas abiertas y cerradas, de respuestas múltiples, compartido vía online. La difusión se hizo por dos vías, de manera directa a través de correos electrónicos de los gerentes y propietarios de los establecimientos, y a través de los grupos de WhatsApp de las diversas asociaciones empresariales turísticas (restaurantes, hoteles, agencias de viajes, entre otros), donde se encuentran registrados empresarios, gerentes y emprendedores.

El cuestionario estableció como objetivo principal la necesidad de recoger las impresiones de los empresarios turísticos del cantón Manta, teniendo en cuenta sus perspectivas y visiones sobre problemáticas concretas como las pérdidas económicas derivadas de la crisis, la estabilidad laboral, la búsqueda de incentivos y las posibles estrategias de reactivación.

\section{Desarrollo.}

\section{Diagnóstico del turismo en Ecuador antes del Covid-19.}

El turismo en Ecuador constituye la tercera fuente de ingresos no petroleros, después del banano y el camarón con un aporte al PIB de más de 2.400 millones de dólares en 2018. La balanza turística de ese mismo año reflejó un saldo positivo de los ingresos frente a los egresos por 1.332,3 millones de dólares. Esta actividad generó en 2018 más de 480.000 empleos directos y 112.000 indirectos, hasta mediados del año 2019, estas cifras se incrementaron a 512.000 y 189.000 respectivamente (Ministerio de Turismo de Ecuador [Mintur], 2019).

En los últimos diez años se ha logrado un crecimiento estable del número de turistas internacionales que visitan Ecuador. Lo cual se mantuvo, incluso en el año 2019, ya que se creía que la crisis política que enfrentó el país, en octubre de ese año, iba a provocar un verdadero retroceso para el turismo ecuatoriano (Hosteltur, 2019). Si bien en este período hubo una caída con respecto al año anterior de un $13 \%$ de visitantes, de forma general el año cerró con un aumento de llegadas de 4,3\% con respecto al 2018. (Federacion de Cámaras de Turismo del Ecuador [Fenacaptur], 2020) 
De este modo se tiene que ingresaron al país en 2019, un total de 1326559 personas. En el rango analizado de este año llegaron 1381726 extranjeros a Ecuador. Las cifras cambian cuando se hace una valoración de la llegada "total de extranjeros" ya que se incluye el arribo de ciudadanos venezolanos. En ese caso, hay un decrecimiento del 14,33\% puesto que en 2018 llegaron 2203559 ciudadanos extranjeros, en tanto que en 2019 lo hicieron 1887843 personas foráneas (Mintur, 2019). Según el Ministerio de Turismo (Mintur, 2019), entre enero y noviembre de 2018 llegaron a Ecuador 884699 ciudadanos venezolanos, mientras que en ese lapso de 2019, cuando se impusieron requisitos migratorios, arribaron 489641 ciudadanos de esa nacionalidad.

Mientras tanto, el turismo interno en 2019 impulsó la economía ecuatoriana en 2800 millones de USD. (Mintur, 2019). De este modo, en los nueve días feriados que se celebran en el país, correspondientes al 2019, se realizaron 13.2 millones de viajes, dirigidos sobre todo a ciudades como Quito, Guayaquil y Cuenca. (Pichincha Comunicaciones, 2019).

En cuanto a la estacionalidad para el turismo internacional se tiene que la temporada alta de turismo en Ecuador comprende desde junio hasta principio de septiembre, y desde fines de diciembre hasta mediados de enero. La temporada baja dura de septiembre a noviembre y de febrero a abril. Las tarifas de hoteles, tours, transporte e incluso restaurantes se reducen durante este período (Velásquez, 2019).

En el Ecuador existen 30000 establecimientos relacionados con el turismo: 5000 hoteles, 20 000 empresas de alimentos y bebidas, 3000 intermediarios turísticos, 400 empresas de recreación y 600 de transporte turístico (ProEcuador, 2019).

Los servicios de alojamiento y de comida se han convertido en un puntal importante en la generación de recursos para el país. El ranking nacional está dominado por 10 de los 221 cantones ecuatorianos. Esas ciudades juntas aportaron el $75 \%$ de recursos al Producto Interno Bruto (PIB) en el segmento de alojamiento y servicio de comida (Banco Central de Ecuador [BCE], 2020).

De este modo, el número de turistas que pasan la noche en Ecuador ha crecido a un ritmo anual de 4,6\% entre 2009 y 2018. Un visitante extranjero permanece en promedio 1,6 días con un gasto diario promedio de 118 dólares (Mastercard, 2019).

Según la Cámara de Turismo de Pichincha y Quito (Captur, 2019) entre los mercados emisores que tienen entre sus preferencias este destino se encuentra Estados Unidos como el primer mercado emisor para Ecuador, con un crecimiento del 4,9\% en 2019 con respecto al año anterior, la nación andina recibió 403.000 turistas estadounidenses. Seguido de España, Canadá, Alemania, Francia, Colombia y Perú.

Así, del total de visitantes recibidos en 2019 aproximadamente 600.000 turistas llegaron al país con el propósito de conocer las diferentes áreas naturales protegidas (Mintur, 2019). 
El medio más utilizado para arribos de turistas internacionales al Ecuador es el aéreo con más del 73.08\% del total de turistas que ingresan en este caso sobresale el aeropuerto de Quito que recibe el 56.95\% del total de turistas que ingresan. En segundo lugar, se encuentra el transporte terrestre y, por último, el transporte marítimo. (Fenacaptur, 2020)

En los últimos años el país ha iniciado operaciones con nuevas aerolíneas como Spirit, GOL y Laser Airlines, ha ampliado la frecuencia de viajes y ha establecido nuevas rutas con Aeroméxico, Aireuropa, Tame y Aerolane, así como un fortalecimiento de las campañas de promoción y publicidad. Sin embrago se considera que en este último campo todavía les queda mucho por aprender y por implementar a los gestores de turismo en la nación, puesto que en materia de comercialización no les hace competencia a los demás países del área (ProEcuador, 2019).

\section{Impacto del covid-19 en Ecuador y en el sector turístico.}

\subsection{Situación actual de la pandemia en Ecuador.}

El país ha presentado una lucha constante desde su primer caso en hasta la actualidad, si bien se siguen registrando contagios la situación no es nada comparable a la del inicio. En Ecuador se reportaron 142305 casos confirmados de COVID-19 hasta el 6 de octubre de este año, 11 736 personas fallecidas a causa del virus y 3796 personas han muerto por causas relacionadas con la enfermedad respiratoria y por otra parte un total de 121000 personas recuperadas. En cuanto a la provincia más afectada es Pichincha con 33947 casos confirmados. Le siguen Guayas y Manabí. Mientras que Quito es la ciudad con más contagios en el país con 31041 y le sigue Guayaquil con 13843 contagios (Ministerio de Salud Publica de Ecuador [MSP], 2020).

El país ha dictado una serie de medidas desde el inicio de la pandemia con el fin de minimizar los daños ocasionados por la enfermedad a su vida política, económica y social. Según los informes de la Secretaría General de Comunicación Ecuador (SectCom, 2020) las principales medidas que ha dictado el país son:

- Confinamiento para toda la población.

- Prohibición de aglomeraciones, fiestas y celebraciones de grupo.

- Uso obligatorio de la mascarilla, multando a aquel que lo incumpla.

- Cierre de fronteras y suspensión de vuelos comerciales.

- Se permitió la entrada de 15 mil ciudadanos ecuatorianos varados en el exterior en vuelos humanitarios.

- Cierre de cinco embajadas y oficinas diplomáticas en Malasia, Irán, Nicaragua, la representación ante la OASI y la secretaría del parlamento.

- Se habilitaron 142 centros para atender a pacientes infectados con la dolencia respiratoria, 118 de ellos pertenecientes a la red de salud pública y aumentó en 1 100 el número de camas. 
- Se habilitaron 353 consultorios para personas sospechosas de contagio.

- Eliminación de la docencia y la jornada laboral presencial.

- En el Sistema Educacional hubo entrega de un millón 300 mil raciones alimenticias a estudiantes.

- Ministerio de Inclusión Económica y Social entregó más de un millón y medio de kits de alimentos para garantizar el acceso a productos de la canasta básica.

- Como parte de un plan de reducción de gastos, se resalta la liquidación de la aerolínea Tame. Cierre de siete empresas públicas: Ferrocarriles, Siembra, Medios Públicos, Crear, Ecuador Estratégico, Correos del Ecuador y la Unidad Nacional de Almacenamiento.

- Eliminación o fusión de 10 instituciones del Estado.

- Se aprobó el proyecto de Ley Orgánica de Ordenamiento de las Finanzas Públicas que contiene medidas acordadas con el Fondo Monetario Internacional, entre las que se encuentran nuevos límites al gasto y la deuda públicos.

- Se aprobó el proyecto de Ley Orgánica de Apoyo Humanitario para Combatir la Crisis Sanitaria Derivada del COVID-19 que plantea ajustes fiscales como la creación de un impuesto a los ingresos de las personas y las utilidades de las empresas, la modificación de condiciones laborables; entre otras.

- Suspensión por 6 meses (abril a septiembre) de todos los pagos de las cuotas de los créditos del sector turístico.

- Reestructuración de todas las obligaciones con nuevos plazos y menores tasas de interés sin que la suspensión de pagos implique el reporte a centrales de riesgo.

\subsection{Situación del sector turístico ecuatoriano.}

La Organización Mundial del turismo calcula pérdidas en este año alrededor de 150 mil millones de dólares a nivel mundial, una cifra que representa 1.5 veces el valor del PIB en Ecuador (El Universo, 2020). Por lo que se puede aludir la precaria situación que presenta el sector turístico en el país tras el paso de la pandemia. El sector tiene el $67 \%$ de las empresas en pausa, en cuanto al alojamiento, muchos hoteles se quedaron con 80 trabajadores de los más de 500 que tenían, otros deshabilitaron la mayoría de sus habitaciones para no cancelar puntos de televisión pagada y de internet, dejando operativa la tercera parte (Federación Hotelera de Ecuador [Ahotec], 2020). Hasta finales de abril el $30 \%$ de los restaurantes estaban cerrados. Estimaciones indican que los ingresos en la industria turística se reducirán este año el 70\% comparado con 2019. Las empresas vinculadas al turismo tienen previsto reducir más del $60 \%$ de su nómina a finales del año (Federación de Cámaras de Turismo [Fenacaptur], 2020).

Con la reactivación de parte de la industria en julio se prevé que llegarían a una ocupación hotelera promediada hasta diciembre de solo el 30\%, y si es en noviembre del 5\%. De volver 
a las condiciones normales, es decir confianza al viajar e inmunidad por tener vacuna, el sector no se recuperaría hasta finales de 2021 (El Universo, 2020).

\subsection{Impacto de la crisis en la imagen turística de Ecuador.}

La situación que presenta Ecuador respecto a la epidemia de COVID-19 es difundida normalmente en los medios de comunicación. Si se tiene en cuenta que el país atravesó por una crisis política en octubre de 2019 lo cual afectó el turismo de forma considerable, se pude afirmar entonces que el país no cuenta con la mejor imagen precedente para enfrentar la crisis epidemiológica, a ello se le suma, que al inicio de la pandemia la situación en Guayaquil se salió de control, debido al número excedido de muertes y la mala gestión de las defunciones. Sin embargo, en los últimos meses, cuando la pandemia no azota con la misma intensidad se pueden ver mejoras y campañas comerciales para situar el destino dentro de la preferencia.

\section{Resultados.}

Los resultados de la aplicación de 300 cuestionarios a gerentes, empresarios y emprendedores de los establecimientos turísticos registrados por el MINTUR, se han obtenido para alcanzar 3 objetivos fundamentales:

1. Valorar la situación del turismo en Ecuador después de la crisis generada por el covid-19.

2. Evaluar posibles escenarios pos-covid.

3. Proponer acciones para enfrentar la futura crisis en el sector.

A continuación, se muestran los resultados obtenidos:

El cuestionario presentado a los encuestados consta de 8 preguntas en las que se evalúan varios criterios en el actuar y el pensar futuro de los principales dirigentes del sector para poder inferir posibles escenarios del turismo en Ecuador y presentar una serie de medidas iniciales que contribuyan a superar la crisis.

\section{1. ¿Qué tan preocupante puede valorar la situación del turismo en Ecuador después de la crisis?}

Tabla 1. Valoración del turismo después de la crisis

\begin{tabular}{lcccc}
\hline & Frecuencia & Porcentaje & Porcentaje válido & Porcentaje acumulado \\
\hline Poco preocupante & 0 & 0 & 0 & 0 \\
Preocupante & 140 & 46.7 & 46.7 & 46.7 \\
Muy preocupante & 160 & 53.3 & 53.3 & 100.0 \\
Total & 300 & 100.0 & 100.0 & \\
\hline
\end{tabular}

Fuente: Elaboración propia. 
Los resultados de la primera pregunta del cuestionario demuestran la conciencia de los dirigentes del sector de la gravedad de la crisis que atraviesa el turismo ante la cancelación de la mayoría de los viajes programados para el año. Nula fue la cantidad de encuestados que marcaron la casilla de poco preocupante, por lo que el $100 \%$ corresponde a las opciones de preocupante y muy preocupante. Se evidencia mayoría en el caso de la de muy preocupante con 160 marcas y un $53.3 \%$, mientras que la de preocupante cuenta con 140 marcas para un $46.7 \%$. Por la preocupación mostrada es de esperarse la colaboración de todos los implicados para la búsqueda y aplicación de soluciones que beneficien al turismo ecuatoriano.

\section{De la siguiente lista seleccione las medidas que emplearía para enfrentar la crisis en el turismo.}

Tabla 2. Medidas que emplearían en las instalaciones turísticas

\begin{tabular}{lcc}
\hline & Frecuencia & Porciento \\
\hline Capacitación de los trabajadores del turismo para preservar la higiene & 300 & 100 \\
adecuada en las instalaciones turísticas & 195 & 65 \\
Reducción de la plantilla laboral & 228 & 76 \\
$\begin{array}{l}\text { Reubicación de los trabajadores para garantizar el distanciamiento social } \\
\text { Suspensión de las campañas de promoción turística }\end{array}$ & 48 & 16 \\
Elevar los estándares de higiene y calidad & 300 & 100 \\
Potenciar el turismo individual más que al turismo grupal & 159 & 53.2 \\
Apoyo financiero del gobierno para sobreponerse a las pérdidas generadas & 249 & 89 \\
por la crisis & & \\
\hline
\end{tabular}

Fuente: Elaboración propia.

De acuerdo con los datos expuestos en la tabla 2 se evidencia que las medidas que más se emplearán en los centros son las de elevar de los estándares de calidad e higiene, y la capacitación de los trabajadores para preservar la higiene adecuada de las instalaciones turísticas, ambas con un $100 \%$ de frecuencia. Con esto se ve la clara necesidad de preservar la higiene hoy más que nunca de los centros turísticos puesto que con el restablecimiento del turismo a nivel internacional será uno de los estándares más medidos por los viajeros a la hora de seleccionar sus destinos. La segunda posición en el orden la ocupa la medida correspondiente a la solicitud de apoyo financiero del gobierno con 249 encuestados para un porcentaje de $89 \%$ : pese a que el presente año significó pérdidas cuantiosas para todos los empresarios del sector turístico en (Viñán, 2020), lo que les recorta la liquidez de sus empresas y les provoca insostenibilidad para afrontar una recuperación exitosa. La reubicación de los trabajadores para garantizar el distanciamiento social es la tercera medida más votada por los encuestados con 228 selecciones para un $76 \%$; esta medida va en correspondencia con las dictadas desde las direcciones de salud tanto a nivel nacional como a nivel regional y mundial por ser de las que garantizan la no propagación del virus. En cuarto lugar se ubica la medida correspondiente a la reducción de la plantilla laboral con un $76 \%$ a partir de los 228 encuestados que votaron por esta. Se preguntó, asimismo, si de tener que 
reducir el personal de su empresa, qué porcentaje representaría esa reducción en su planilla actual, utilizando una escala de 1 (10\%) el valor más bajo y 10 (100\%) el valor más alto. A pesar de que muchos no precisaron la cantidad aproximada porcentual necesaria en la que podían reducir dicha plantilla, todos afirmaron de esta necesidad para poder sobreponerse a la crisis. Los resultados del porciento a reducir se muestran en la tabla 3. En la quinta posición se encuentra "potenciar el turismo individual más que el turismo grupal" con 159 encuestados para un 53.2\% esta medida no es asumida por todos a pesar de la necesidad del distanciamiento porque muchos nichos del mercado actual constan de grupos de viajeros, los cuales hay que revisar la tendencia de su comportamiento. Por último, se encuentra la suspensión temporal de las campañas promocionales, con 48 encuestados y un $16 \%$.

Tabla 3. ¿Qué porcentaje representaría la reducción de la fuerza laboral?

\begin{tabular}{lcccccc}
\hline & & N & Mínimo & Máximo & Media & Desviación estándar \\
\hline $\begin{array}{l}\text { ¿Qué porcentaje representaría } \\
\text { reducción con su planilla actual? }\end{array}$ & 300 & 1,00 & 10,00 & 4,0049 & 2,695428 \\
\hline
\end{tabular}

Nota: Escala de $1(10 \%)$ a $10(100 \%)$.

Fuente: Elaboración propia.

3. ¿Cree importante la promoción del turismo a través de los medios digitales y plataformas sociales?

Tabla 4. Promoción del turismo a través de los medios digitales y plataformas sociales.

\begin{tabular}{lcccc}
\hline & Frecuencia & Porcentaje & $\begin{array}{c}\text { Porcentaje } \\
\text { válido }\end{array}$ & $\begin{array}{c}\text { Porcentaje } \\
\text { acumulado }\end{array}$ \\
\hline Poco importante & 0 & 0 & 0 & 0 \\
Importante & 69 & 23 & 23 & 23 \\
Muy importante & 231 & 77 & 77 & 100 \\
Total & 300 & 100 & 100 & \\
\hline
\end{tabular}

Fuente: Elaboración propia.

Para identificar el nivel de importancia que tienen las redes sociales y medios digitales para la promoción del turismo en Ecuador el cuestionario contenía la pregunta 3. Los resultados de la misma se muestran en la tabla 4. El 100\% de los encuestados reconocen la importancia de este tipo de promoción para el desarrollo turístico puesto que nadie marco la opción de "poco importante"; además es reconocible que en la mayoría de los encuestados opinan que es "muy importante" con un $77 \%$ a partir de las 231 encuestas con esa respuesta a la pregunta. Mientras que los otros 69 la valoraban de importante para un $23 \%$.

\section{4. ¿Qué incentivos utilizaría para reactivar su negocio?}


Tabla 5. Incentivos para reactivar su negocio.

\begin{tabular}{llll}
\hline & Frecuencia & Porcentaje & Porcentaje válido \\
\hline Crediticios (créditos con meses de gracia) & 229 & 76.5 & 100 \\
Económicos (Bonos de incentivo) & 168 & 56.1 & 100 \\
Legal (asesoría jurídica) & 19 & 6.3 & 100 \\
Técnico (capacitaciones tecnológicas) & 11 & 3.7 & 100 \\
Publicitarios (marketing digital, impreso) & 119 & 39.7 & 100 \\
\hline
\end{tabular}

Fuente: Elaboración propia.

Otro de los aspectos analizados en esta investigación consistió en la valoración de una serie de incentivos claves para reactivar y desarrollar la actividad empresarial turística, para lo cual se preguntó a los actores encuestados qué tipo de incentivos necesitaría para reactivar su negocio, pidiendo escogieran un máximo de 2 opciones. La frecuencia con la que se señala cada incentivo se presenta en la Tabla 5 y la figura 2, concentrándose en los de carácter crediticio y en las ayudas económicas (subvenciones). Los resultados, por otro lado, evidencian la urgencia de los empresarios a la hora de acceder a nuevos créditos blandos, refinanciación de deudas e incentivos para reactivar sus negocios.

\section{5. ¿Ve usted oportuna la disminución del precio de su negocio con la reapertura turística?}

Tabla 6. Disminución de los precios de su negocio

\begin{tabular}{lcc}
\hline & Frecuencia & Porcentaje \\
\hline Si & 231 & 77.2 \\
No & 69 & 22.8 \\
\hline
\end{tabular}

Fuente: Elaboración propia.

La disminución de los precios de los negocios es vista evidentemente como una oportunidad de competitividad con la reapertura turística.

En una apreciación global y a corto plazo, con una demanda restringida y con menor capacidad de gasto por la crisis económica, que también estimula la propensión al ahorro como consecuencia de la incertidumbre, será inevitable una caída en los precios respecto a la situación pre-coronavirus2, si bien dicha reducción dependerá de cómo se ajuste la oferta (por ejemplo, no parece razonable que toda la capacidad hotelera vaya a estar disponible a la vez desde el minuto uno) y como sea, por tanto, el nivel de rivalidad competitiva (el sector, con inteligencia, debería ir acompasando la oferta que inyecta en el mercado a la recuperación progresiva de la demanda) (Vargas, 2020).

No obstante, es de señalar que esta estrategia no es la única para competir en el sector. Es necesario el enfoque en otras más eficientes en el mediano y largo plazo puesto que con la 
recuperación los diferentes destinos turísticos serán vital en la percepción de los visitantes otros indicadores más necesarios como son la higiene, y la seguridad. De esta forma si con la disminución de los precios para aumentar la competitividad el destino se posiciona en el mercado por esta característica, le será casi imposible variar estos precios en el mediano y largo plazo sin afectar su propia demanda.

\section{Se puede considerar de inevitable la modificación en el actuar y el pensar de los turistas y de la forma de gestionar el turismo desde cada estado y a nivel de país:}

- Considera que los cambios en la forma de pensar de los turistas a la hora de viajar serán temporales o permanentes.

Tabla 7. Cambios en la forma de pensar de los turistas

\begin{tabular}{lll}
\hline & Frecuencia & Porcentaje \\
\hline Temporales (coyuntural) & 158 & 52.7 \\
Permanentes (estructural) & 142 & 47.3 \\
Total & 300 & 100 \\
\hline
\end{tabular}

Fuente: Elaboración propia.

- Considera que los cambios y medidas de asumidas tanto a nivel gubernamental como a nivel empresarial serán:

Tabla 8. Cambios y medidas de asumidas tanto a nivel gubernamental como a nivel empresarial

\begin{tabular}{lll}
\hline & Frecuencia & Porcentaje \\
\hline Temporales (coyuntural) & 136 & 45.3 \\
Permanentes (estructural) & 164 & 54.7 \\
Total & 300 & 100 \\
\hline
\end{tabular}

Fuente: Elaboración propia.

La tabla 7 expresa según la apreciación de los encuestados el posible comportamiento de la demanda en cuanto a su forma de pensar; valorándola en dos indicadores fundamentales: cambios temporales en su forma de pensar: con 158 opiniones en favor de esta opción para un 52.7\%; y cambios permanentes en su forma de pensar: con 142 votos y un porcentaje de 47.3. Por la similitud de estas respuestas es considerable la incertidumbre que se vive en cuanto al futuro del turismo. Para precisar en el camino que tomaría esta apreciación sería necesario encuestar a los propios visitantes usuales de este destino turístico.

En la tabla 8, que expresa la posibilidad de la permanencia o no de las medidas tomadas tanto en el gobierno como en las empresas, se evidencia una ligera tendencia a que los cambios tomados sean estructurales (164 encuestados para un 54.7\%) y no coyunturales (136 encuestados para el 45.3\%). Esta tendencia puede estar dada por el claro beneficio que 
aportan en sentido general la mayoría de las medidas sanitarias para la crisis pero que contribuyen con la prevención de otras enfermedades, eleva los estándares de higiene y calidad y procura un ambiente más sano en todos los ámbitos de la vida cotidiana.

En la pregunta se trabajan dos factores que al combinarse generan 4 escenarios posibles: tabla 9.

Tabla 9. Escenarios

\begin{tabular}{|c|c|c|c|}
\hline \multirow{2}{*}{\multicolumn{2}{|c|}{ Cambio en }} & \multicolumn{2}{|c|}{$\begin{array}{l}\text { El comportamiento del turista } \\
\text { (más cauteloso y sensible frente a la seguridad y la salud) }\end{array}$} \\
\hline & & Estructural & Coyuntural \\
\hline \multirow{4}{*}{$\begin{array}{l}\text { La política } \\
\text { Gubernamental } \\
\text { (restricciones a } \\
\text { la circulación } \\
\text { De personas) }\end{array}$} & & Escenario 1: & Escenario 2: \\
\hline & Estructural & $\begin{array}{l}\text { Reconfiguración del sector } \\
\text { (cuantitativa y cualitativa) }\end{array}$ & $\begin{array}{l}\text { Contracción } \\
\text { cuantitativa }\end{array}$ \\
\hline & & Escenario 3: & Escenario 4: \\
\hline & Coyuntural & $\begin{array}{l}\text { Cambio cualitativo de la demanda } \\
\text { turística }\end{array}$ & $\begin{array}{l}\text { Vuelta a la situación } \\
\text { pre-covid-19 }\end{array}$ \\
\hline
\end{tabular}

Fuente: (Vargas, 2020)

Empezando por el final (escenario 4), si las restricciones gubernamentales al movimiento de personas fueran pasajeras y/o no significativas, así como los miedos o cautelas del turista generados por la pandemia, en relativamente poco tiempo se volvería a la situación pre-crisis (Vargas, 2020).

Si los corsés de los gobiernos van progresivamente remitiendo pero el trauma del coronavirus se instala en la mente del turista (aparte de en su bolsillo por la crisis económica), nos encontraríamos en un escenario 3 , en el que la demanda turística habría cambiado cualitativamente, con criterios en la decisión de compra (y por tanto con atributos en los productos y destinos turísticos) que habría que revisar (Vargas, 2020).

Si el comportamiento del turista sólo se viera afectado coyunturalmente, pero las políticas de los gobiernos siguieran frenando los flujos de viajeros, nos encontraríamos en un escenario 2 , de contracción cuantitativa de la demanda, particularmente a nivel internacional, que alteraría los flujos turísticos pre-crisis. La movilidad doméstica o de más corto radio se vería incentivada por estas políticas. Asimismo, aunque por otra razón (la prudencia acrecentada del turista), el escenario precedentemente citado (3) también podría alimentar esta situación, favorecedora del turismo doméstico o de proximidad. En cualquier caso, sería una demanda inicialmente limitada y condicionada por la crisis económica derivada de la sanitaria (Vargas, 2020).

Finalmente, el escenario 1 sería el más complejo, con cambios estructurales tanto en la acción de los gobiernos como en el comportamiento del turista. El sector estaría llamado a una cierta reconfiguración de su oferta para adaptarse a estos cambios cuantitativos y cualitativos. 
Aquello de reinventarse o morir volvería a tomar carta de naturaleza, teniendo bien presente que la percepción de confianza que transmitan empresas y destinos, apaciguadora del miedo a viajar, será fundamental en la recuperación. Asimismo, la actitud de las comunidades receptoras de los flujos turísticos debería observarse con atención, para evitar reacciones adversas como las ya expresadas: el turismo no sólo vive de los turistas; también necesita de la complicidad de los residentes (Vargas, 2020).

Valorando las respuestas dadas en la pregunta es ligeramente superior la tendencia a que el futuro turístico de Ecuador se encuentre en el primer o segundo escenario.

\section{Como actuaría usted ante la los posibles cambios en la demanda turística si:}

- La demanda turística del destino se recupera gradualmente con cambios cualitativos en cuanto a su forma de pensar (valorando más la percepción de riesgo y la seguridad en el destino)

Tabla 10. Actuar ante la recuperación gradual de la demanda

\begin{tabular}{lcc}
\hline & Frecuencia & Porcentaje \\
\hline Reactivamente & 171 & 57.3 \\
Proactivamente & 129 & 42.7 \\
Total & 300 & 100 \\
\hline
\end{tabular}

Fuente: Elaboración propia.

La tendencia en cuanto a la toma de decisiones con respecto a la recuperación de la demanda es hacia la acción reactiva; es decir, la evaluación constante de los cambios que se puedan originar en la demanda a medida que se recupera para una actuación en correspondencia con los mismos. El indicador reactivo alcanzo 171 encuestados para un $57.3 \%$ mientras que el proactivo alcanzó 129 encuestados para un $42.7 \%$.

- La demanda turística del destino no se repone gradualmente pese a los cambios cualitativos en cuanto a su forma de pensar (valorando más la percepción de riesgo y la seguridad en el destino)

Tabla 10. Actuar ante la no recuperación gradual de la demanda

\begin{tabular}{lcc}
\hline & Frecuencia & Porcentaje \\
\hline Reactivamente & 138 & 46 \\
Proactivamente & 162 & 54 \\
Total & 300 & 100 \\
\hline
\end{tabular}

Fuente: Elaboración propia. 
En este caso la tendencia es a la búsqueda proactiva de soluciones para incentivar el flujo de la demanda hacia el destino. Por esta respuesta optaron 162 encuestados para un 54\%, mientras que por la solución reactiva ante la situación optaron 138 encuestados para un $46 \%$.

Con esta pregunta se suponen dos tipos de cambios en la demanda turística: cambios solo cualitativos (modificaciones en su forma de pensar, pero sin influir en su preferencia) y cambios cualitativos y cuantitativos (no solo se modifica su forma de pensar sino también sus intereses de viaje provocando una disminución de la demanda). Según (Vargas, 2020) estas situaciones entrecruzadas con la conducta proactiva o reactiva asumida por los gestores y dirigentes del turismo determina la posibilidad de 4 nuevos escenarios posibles: tabla 11 .

Tabla 11. Escenarios (II)

\begin{tabular}{clll}
\hline $\begin{array}{c}\text { El turismo post }- \text { covid 19: } \\
\text { escenarios posibles. }\end{array}$ & \multicolumn{1}{c}{$\begin{array}{c}\text { Dimensión interna } \\
\text { (cultura organizacional) }\end{array}$} \\
\hline $\begin{array}{c}\text { Dimensión } \\
\text { externa } \\
\text { (cambio en }\end{array}$ & Cualitativos & $\begin{array}{l}\text { Escenario 1: } \\
\text { Mantenimiento del modelo actual, con } \\
\text { algunas modificaciones }\end{array}$ & $\begin{array}{l}\text { Escenario 2: } \\
\text { Avance lento hacia un nuevo } \\
\text { modelo }\end{array}$ \\
$\begin{array}{c}\text { la demanda } \\
\text { turística) }\end{array}$ & $\begin{array}{l}\text { Cualitativos y } \\
\text { cuantitativos }\end{array}$ & $\begin{array}{l}\text { Escenario 3: } \\
\text { Avance lento hacia un nuevo modelo }\end{array}$ & $\begin{array}{l}\text { Escenario 4: } \\
\text { Avance rápido hacia un nuevo } \\
\text { modelo }\end{array}$ \\
\hline
\end{tabular}

Fuente: (Vargas, 2020)

A partir de los resultados obtenidos en la pregunta el escenario todos los escenarios tienen cierto margen de probabilidad, pero de ellos los más probables son el escenario 1 y el escenario 4.

El escenario 1: supondría volver a lo que se le llamaba "business as usual", esto es, al mantenimiento de los enfoques pre-crisis con algunas modificaciones en las estrategias de marketing para adaptarse a posibles nuevos rasgos comportamentales de un turista marcado por las consecuencias del covid-19 (Vargas, 2020).

Escenario 4: una cultura organizacional proactiva permitirá un avance más rápido hacia ese nuevo modelo, siempre que puedan contar con los recursos para ello. Estas empresas representarán la avanzadilla que marcará el camino al resto (Vargas, 2020).

\section{Propuesta de acciones para el turismo ecuatoriano después de la crisis por covid-19.}

Ante los escenarios descritos anteriormente los investigadores proponen las siguientes acciones para la recuperación del sector:

- Capacitar a los trabajadores del turismo para preservar la higiene adecuada en las instalaciones turísticas. 
- Elevar los estándares de higiene y calidad.

- Apoyar desde el gobierno económica y financieramente a las empresas tanto privadas como estatales.

- Reorganizar adecuadamente la plantilla laboral para garantizar el distanciamiento físico necesario.

- Debido a la tendencia a aumentar el desempleo: evaluar medidas gubernamentales que protejan a los trabajadores del sector.

- Garantizar la seguridad sanitaria de los viajeros y los trabajadores, a través de protocolos de higiene y comportamiento para hoteles, playas y demás áreas del sector.

- Incrementar la promoción de los destinos a través de campañas digitales.

- Apostar por el turismo de negocios, aquellos viajes comerciales que son impostergables y los movimientos internos de los empleados del resto de las empresas.

- No asumir la disminución del precio como única vía para potenciar la demanda turística.

- Realizar estudios de demanda para poder estimar futuros cambios en esta.

- Actuar de manera proactiva ante cualquier tendencia que marque la demanda, sea al aumento, mantenimiento o disminución con respecto a años anteriores.

- Realizar estudios de nuevos mercados potenciales para contrarrestar las fluctuaciones de la demanda convencional del destino.

- Evaluar correctamente las medidas de carácter temporal y las de carácter permanente dentro del sector turístico.

\section{Conclusiones.}

- El desarrollo de la presente investigación permitió arribar a las siguientes conclusiones:

- El turismo en Ecuador constituye la tercera fuente de ingresos no petroleros, que ha logrado un crecimiento estable en la última década, donde juega un rol muy importante el turismo interno; además de las variedades naturales y culturales del país que le confieren gran atractivo.

- El país ha sido afectado de manera sostenida por el virus COVID-19, y sus efectos a la economía y la sociedad son considerables; los cuales ha tratado de minimizar con medidas para situaciones excepcionales como esta.

- La situación epidemiológica ha representado una crisis sin precedentes para el turismo ecuatoriano, cuya situación actual muestra un escenario desfavorable, lo que ha provocado el deterioro de la ya dañada imagen de Ecuador como destino turístico internacional.

- Los resultados de los cuestionarios aplicados a gerentes, empresarios y emprendedores de los establecimientos turísticos, reflejan que la situación en el país es considerada como muy preocupante, que la capacitación del personal y la 
reducción de plantillas figuran entre las principales medidas de las instalaciones para la reactivación, así como la promoción por vía digital.

- Según los encuestados, se concluye que los cambios en la forma de pensar de los turistas, así como las medidas de los países y de las empresas, se consideran coyunturales, por lo que los escenarios más propensos a ocurrir son: la vuelta a la situación pre - covid y el Cambio cualitativo de la demanda turística.

- Las estrategias de reactivación y recuperación del turismo en Ecuador se hacen en correspondencia con la evaluación de los posibles escenarios a ocurrir en el país.

\section{Referencias bibliográficas.}

Banco Central de Ecuador [BCE]. (5 de enero de 2020). Infrorme de cierre 2019. Recuperado el 27 de septiembre de 2020, de BCE: http://www.bcf.fin.ec.com/

Federacion de Cámaras de Turismo del Ecuador [Fenacaptur]. (10 de febrero de 2020). Estadisticas de turistas extrajeros en Ecuador 2019. Recuperado el 30 de septiembre de 2020, de FreeLance: http://www.freelance.com

Félix, M. Á., \& García, R. N. (junio de 2020). Estudio de pérdidas y estrategias de reactivación para el sector turístico por crisis sanitaria COVID-19 en el destino Manta-Ecuador. Obtenido de Revista Internacional de Turismo, Empresa y Territorio: https://doi.org/10.21071/riturem.v4i1.12743

INEGI. (31 de julio de 2019). Los mexicanos gaan menos, pero gastan más. . Obtenido de Expansión : http://www.expansio.mx.com/

Instituto del Turismo de España. (15 de noviemnbre de 2019). México, mercado emiso. Obtenido de Turespaña: http://www.tourspain.cpm/

Instituto Nacional de Estadística y Geografía. (15 de Julio de 2019). Encuesta Nacional de la Dinámica Demogáfica. Obtenido de INEGI: http://www.enegi.com/

Ministerio de Salud Publica de Ecuador [MSP]. (6 de octubre de 2020). Evolucion de casos de coronavirus. Recuperado el 6 de octubre de 2020, de EL Cormercio: http://www.elcomercio.com

Ministerio de Turismo de Ecuador [Mintur]. (26 de junio de 2019). Balanza de Pagos del Banco Central de Ecuador. Recuperado el 5 de octubre de 2020, de MINTUR: http://www.minturec.com

MINSAP. (8 de octubre de 2020). Parte al cierre del dia 7 de octubre a las 12 de la noche. Obtenido de Sitio oficial de gobierno del Ministerio de Salud Púbica: http://salud.msp.gob.cu 
Mintur. (23 de diciembre de 2019). Llegada de extranjeros a Ecuador aumentó un $4 \%$ en 2019 . Recuperado el 30 de septiembre de 2020, de MINTUR: http://www.minturec.com

Mintur. (29 de diciembre de 2019). Turismo interno en Ecuador. Recuperado el 3 de octubre de 2020, de GeoVit: http://www.geovit.com

Northstar Research Partners. (17 de Julio de 2019). Vacation deprivation : un nuevo estudio sobre las vacaciones a nivel global. Obtenido de Explore by Expedia: https://www.esxpedia.es/

Oficina de Información Diplomática. (20 de julio de 2019). Ficha País, México. Obtenido de http://www.exteriores.gob.es/

OMT. (2 de Mayo de 2019). Barómetro del Turismo Mundial. Obtenido de UNWTO: https://www.e-unwto.org/

OMT. (20 de Diciembre de 2019). Panorama del Turismo Internacional. Obtenido de UNWTO: https://www.e-unwto.org/

Pichincha Comunicaciones. (30 de diciembre de 2019). Cifras del turismo interno en Ecuador. Recuperado el 3 de octubre de 2020, de GeoVit: http://www.geovit.com

Secretaría del Turismo. (16 de Marzo de 2019). Compendio Estadístico del Turismo en México 2018. Obtenido de Datatur: https://www.datatur.sectur.gob.mx/

Secretaría del Turismo. (20 de 1 de 2020). Visón Global del Turismo. Obtenido de Datatur: https://www.datatur.sectur.gob.mex/

Sustentur. (2 de enero de 2020). Las tendencias de viajes de loe mexicanos en 2020. Obtenido de Sustentur: http://www.sustentur.com.mx/

Tuquinga, J. E. (25 de febrero de 2019). PERFIL SOCIODEMOGRÁFICO DEL TURISTA DE LA PROVINCIA DE SANTA ELENA EN ECUADOR. REFERENCIAS PARA NUEVAS PROPUESTAS DE DESARROLLO. Recuperado el 24 de septiembre de 2020, de Univerisdad y sociedad: http://www.univsoc.com

Vargas, A. (2020). Entender el turismo pos-coronavirus: Posibles Escenarios. AECIT.

Velásquez, M. V. (23 de junio de 2019). Crónicas a pie. Recuperado el 27 de septiembre de 2020, de Wordpress: http://www.conicasapiedefosa.wordpress.com

【Liencia 


\section{Para citar el artículo indexado}

Armstrong Zulueta, D., \& Rodríguez Deler, T. (2020). Diagnóstico y evaluación de la situación del turismo en Ecuador y propuesta de acciones para enfrentar la crisis generada por el covid-19. AlfaPublicaciones, 1(1), 47-64. https://doi.org/10.33262/ap.v1i1.19

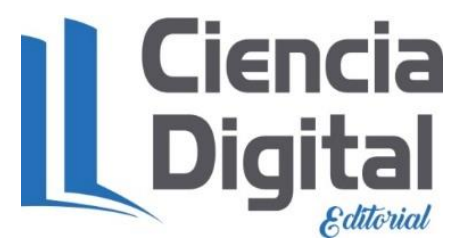

El artículo que se publica es de exclusiva responsabilidad de los autores y no necesariamente reflejan el pensamiento de la Revista Alpha Publicaciones.

El artículo queda en propiedad de la revista y, por tanto, su publicación parcial y/o total en otro medio tiene que ser autorizado por el director de la Revista Alpha Publicaciones.
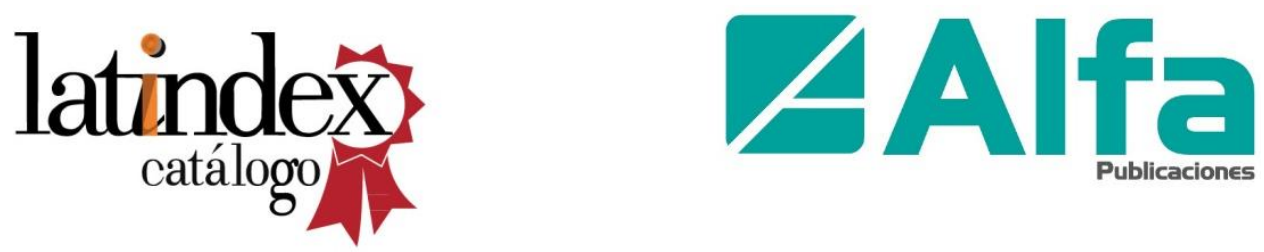